\title{
Failure Analysis of Diode Components of Electronic Relay Packages Via Thorough Microstructural Characterization
}

\author{
อ \\ Received: 16 February 2019 \\ Accepted: 03 September 2019 \\ Published: 27 September 2019 \\ Publisher: Deer Hill Publications \\ (C) 2019 The Author(s) \\ Creative Commons: CC BY 4.0
}

Mrityunjoy Hazra and Satyapal Singh

\begin{abstract}
Diode components used in the electronic relay packages of avionics of a weapon system had been found corroded. Two sets of the complete assembly of the damaged diode parts consisting of diode body, plain washer, spring washer and mounting nuts were analysed for finding out the root causes of failures. Detailed metallographic characterization of the failed materials was carried out using optical microscope, scanning electron microscope (SEM), energy dispersive spectroscopy (EDS) analysis within SEM and microhardness study. It was found that inadequate electroless nickel (EN) plating along with significant amount of porosity and presence of MnS type of stringers affected the corrosion resistance of the diode body tremendously for both the sets. Inadequate electroplated $\mathrm{Zn}$ layer was observed on spring washer, plain washer and nut, wherein both uniform and pitting corrosion were detected. Important recommendations included: (i) thicker (more than $25 \mu \mathrm{m}$ ) EN coating with as-specified porosity level for diode body, (ii) replacement of electroplated zinc layers with galvanized zinc layer (of higher thickness) on all the fasteners, (iii) precaution in minimizing formation of galvanic couplings observed in the present system, like that between EN-coated diode body and zinc coated fasteners, between mild steel and stainless steel fasteners etc.
\end{abstract}

Keywords. Electronic Relay Package corrosion, Electroless nickel plating, Diode, Spring washer, Plain washer, Nut.

\section{BACKGROUND}

Diodes of different sizes and capacities, used in the electronic relay packages of avionics of a weapon system had been found corroded, after qualification testing of the packages. Two sets of the complete assembly of the damaged diode parts including diode body, plain washer, spring washer and mounting nuts along with few unused (asfabricated) ones were investigated for detecting root causes of corrosion. This report presents the results of the failure investigation.

\section{LITERATURE SURVEY}

\subsection{Power Diode}

A power diode has larger PN junction area as compared to its smaller signal diode cousin [1]. This results in a high forward current capability of up to several kilo-amps and a reverse blocking voltage of up to several kilo-volts. It is not suitable for high frequency applications above $1 \mathrm{MHz}$, but special and expensive high frequency high current diodes are available for the said purpose. They can also be used as free-wheeling diodes and snubber networks, due to their high current and voltage characteristics. The failed present diode system is a typical commercially available general purpose standard recovery high current rectifier 1N2131 200V 60A Cathode Stud type [2]. It usually comes with mounting hardware like plain washer, spring washer and nut (Figure 1). It is usually used in applications such as dc power supplies, inverters, converters, ultrasonic systems, choppers and as a free-wheeling diode.

\subsection{Electrical/Electronic Relay Package System}

There are varieties of electrical and electronic devices which are classed as output devices used to control or operate some external physical process. These output devices are also known as Actuators. Its basic function is to convert an electrical signal into a corresponding physical quantity such as movement, force, sound etc. An actuator is also classed as a transducer because it changes one type of physical quantity into another and is usually activated or operated by a low voltage command signal. Actuators can be classed as either binary or continuous devices based upon the number of stable states their output has.

Hazra M. $ه$ and Singh, $S$.

Defence Metallurgical Research Laboratory

PO: Kanchanbagh, Hyderabad 500 058, India

E-mail: mhazra@dmrl.drdo.in

Reference: Hazra, M. and Singh S. (2019). Failure Analysis of Diode Components of Electronic Relay Packages Via Thorough Microstructural Characterization. International Journal of Engineering Materials and Manufacture, 4(3), 124-136. 
A relay is a binary actuator as it has two stable states, either energised and latched or de-energised and unlatched, while a motor is a continuous actuator because it can rotate through a full $360^{\circ}$ motion (Figure 2). The most common types of actuators or output devices are electrical relays, lights, motors and loudspeakers. Electrical Relays can be divided into mechanical action relays called "Electromechanical Relays" and those which use semiconductor transistors, thyristors, triacs, etc., as their switching device called "Solid State Relays" or SSRs.

\subsection{Corrosion of Electronic Components}

Corrosion of complex electronic equipment is an increasingly serious problem, causing extensive damage, while there is an enormous increase in number and variety of applications of electronic equipment in commercial, industrial, and domestic environments. Literature survey has shown that the corrosion of electronic equipment is a serious problem, causing extensive damage which is estimated at $\$ 5$ billion in the United States alone for equipment repairs, downtime and replacements [3]. It occurs throughout the entire life cycle during different stages of manufacturing, assembly, transport and storage of components and assemblies and during field operations of the equipment. Presence of moisture, chloride, sulphur dioxide, hydrogen sulphide and other airborne corrosives, meteorological parameters etc influence the occurrence of corrosion.

As electronics continue to shrink in size and grow in capacity, the importance of corrosion control increases [4]. Miniaturization of systems based on integrated circuits and small size components, close component spacing, separable electrical contacts having lower voltages and contact forces than before have resulted in failures of electronic equipment due to the formation of small quantities of corrosion products. Materials used in electronic equipment manufacture are used for their electrical or magnetic properties. Complexity, moisture, airborne corrosives, impressed currents, etc. influence the occurrence of corrosion. Alloying them with chromium is not possible with these devices/equipment due to deleterious effects on the properties of interest. The failures of thin film circuits and printed circuit boards are divided into two classifications - (i) dry electro migration occurring in the absence of moisture or electrolyte, (ii) simultaneous corrosion and electro deposition in the presence of moisture to yield electrolyte of reasonable conductivity.

With the increasing rate of corrosion in these microelectronic equipment/devices/components there is slow deterioration of electronics which poses great threat in future with unpredictable consequences. In conclusion, a car can function even when pounds of metal are lost to corrosion but an electronic device fails with a minimum loss of 1 pico gram of the material.

\subsubsection{Causes for Corrosion in Electronic Devices}

There may be one or more than one reasons for failure of a component. Principle reasons for corrosion in electronic devices are: (i) service of devices such as integrated circuits (IC) in which metallic lines are often biased electrically relative to nearby lines, (ii) aggressive manufacturing processes, (iii) exposure to uncontrolled environments such as temperature, humidity and contamination, (iv) due to device miniaturization and its effect on the width and separation of metal lines on ICs (have been cut in half approximately every 5 years and not less than 1 micron in the most advanced devices) [5,6], ( $v$ ) reactive gaseous agents $-\mathrm{NO} \times, \mathrm{SO}_{x}, \mathrm{O}_{3}, \mathrm{H}_{2} \mathrm{O}_{2}, \mathrm{NH}_{3}, \mathrm{H}_{2} \mathrm{~S}$ plus volatile organic compounds; suspended inorganic and organic acids $\left(\mathrm{H}_{2} \mathrm{SO}_{4} \mathrm{HCl}, \mathrm{HNO}_{3}\right)$, suspended submicron hygroscopic ionic particles $\left(\mathrm{NH}_{4} \mathrm{HSO}_{4}, \mathrm{NH}_{3} \mathrm{NO}_{4},\left(\mathrm{NH}_{4}\right)_{2} \mathrm{SO}_{4}\right.$ plus others); other inorganic compounds and metals $-\mathrm{NaCl}, \mathrm{Fe}, \mathrm{Al}, \mathrm{Mg}$, $\mathrm{Ca}, \mathrm{K}$ suspended in the air.

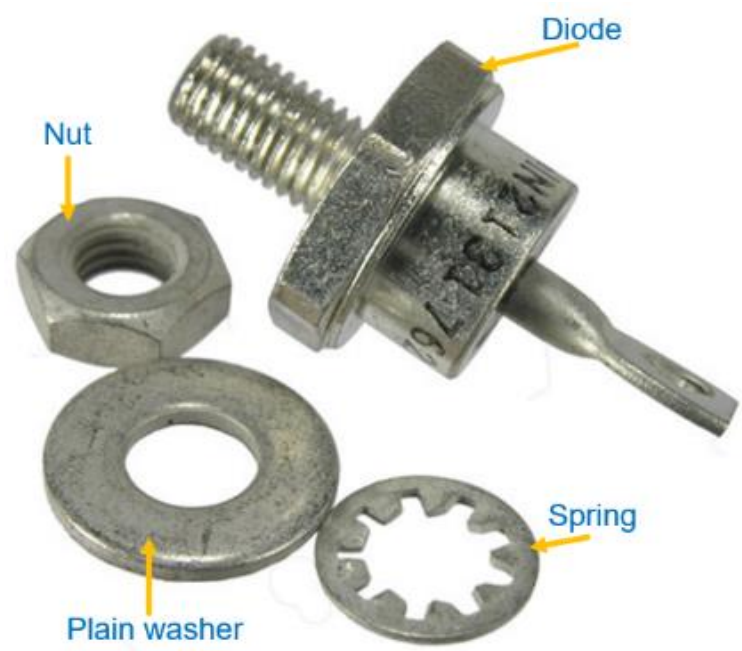

Figure 1: Commercially available 1N2131 200V 60A cathode stud system, similar to the presently investigated systems. 


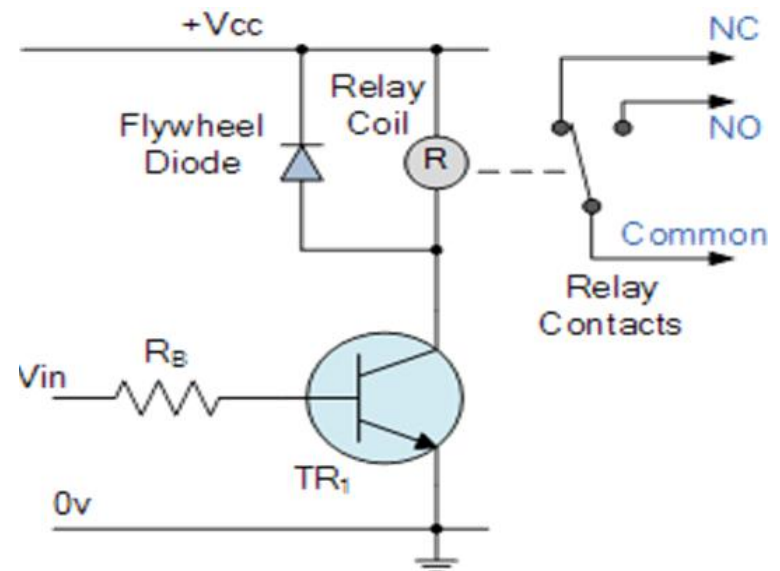

Figure 2: A typical Electrical Relay Package circuit.

\subsubsection{Factors influencing the rate of corrosion}

Some important factors influencing the rate of corrosion are: (i) presence of contaminants, (ii) contamination from assembly, (iii) contamination from handling and storage, (iv) presence of airborne contaminants.

\subsubsection{Corrosion Control}

Complexity in design, moisture, airborne corrosives, impressed currents etc. influence the occurrence of corrosion in electronic devices in such a way that protection against and control of corrosion becomes challenging. Nevertheless, introduction of computer chip type of micro-devices has warranted development of new methods of corrosion protection for equipment exposed to outdoor or polluted environments [6].

Prevention methods including hermetic sealing of components in cavities, use of protective coatings, encapsulation, use of noble metal plating, increased use of more corrosion resistant metal alloys and the use of moisture absorbing desiccants have all served to decrease, but not eliminate corrosion in electronic components.

Volatile corrosion inhibitors ( $\mathrm{VCls}$ ) provide an effective and probably the most suitable means of protecting electronic components from corrosion. $\mathrm{VCls}$ represent a method of chemically conditioning the environment that consequently become less corrosive to the metals. Mixed inhibitors are best suited for the requirements of electronic industry. This direct method of corrosion protection by means of metal passivation in many cases is superior to traditional indirect methods of corrosion protection such as the use of drying agents and the protective coatings. The compounds capable of inhibiting both cathodic and anodic reactions have optimum effectiveness, when a phenomenon in electronic equipment is simulated by the design.

\subsubsection{Corrosion Types in Electronic Devices}

There are some common examples of revelation of corrosion phenomenon in electronic industries. Some of those are [6]: (i) micro pitting on aluminium on IC, (ii) voltaic corrosion in ICs, (iii) pore creep in electrical contacts and metallic joints, (iv) solder corrosion, ( $v$ ) printed circuit board (PCB).

\subsubsection{Method of Analysis of Corrosion in Electronic Devices}

Various ways of corrosion analysis and monitoring are available. Some of those are [6]: (i) water drop migration to analyse dendrite formation electrochemical techniques, (ii) AC impedance analysis of residues on PCBs, (iii) submicron dust particle exposure chamber, (iv) ion chromatography to determine ionic contamination, ( $v$ ) corrosive gas test, (vi) field and laboratory corrosion methods for contact materials (gold and tin plated), (vii) determination of Hermicity of electron devices by dye penetration.

\section{EXPERIMENTAL PROCEDURE}

All the received parts were, at first, examined visually by naked eye and under magnifying glass. Photographs in the as-received condition were taken and preserved for future reference during the course of analysis. Afterwards, the parts were held under forced air using a typical metallographic dryer, so as to remove the loosely held foreign matters, sitting on the surface as a result of consequential effect. Then, all the parts were examined under scanning electron microscope (SEM) to obtain the composition of the clearly visible surface corrosion debris. After that, representative cross-sectional sample extraction was carried out from the severely corroded regions for detailed metallographic (optical microscopic and scanning electron microscopic) study in both unetched and etched condition. Compositional analyses on each part were carried out with EDS attachment of the SEM. Bulk compositional analysis for all the components was carried out with the help of inductively coupled plasma optical emission spectroscopy (ICP OES) technique. Vickers microhardness readings on each of the samples were taken at 300 gf load value. 


\section{EXPERIMENTAL RESULTS}

\subsection{Visual Examination}

Photographs of all the as-received components are shown in Figure 3 and Figure 4 for set 1 and set 2 parts respectively. The observations are as tabulated below in Table 1. It is to be noted that the spring washer among all the components of set 1 seems to have experienced least corrosion damage, while plain washer of set 2 assembly did not reveal any sign of corrosion. The appearance of cross-sectional samples after mounting in bakelite hot mount for detailed metallographic study is as shown in Figure 5. It is to be noted that the stud part for diode body of set 2 assembly is tapered unlike that for set 1 .

Table 1: Visual observations as captured by photography

\begin{tabular}{|c|c|c|}
\hline \multicolumn{2}{|c|}{$\begin{array}{l}\text { Nomenclature (identification) of the } \\
\text { parts }\end{array}$} & Visual Observations \\
\hline Diode body & $\begin{array}{l}\text { Set } 1 \\
\text { Set } 2\end{array}$ & $\begin{array}{l}\text { Diode shell is tarnished with a black product, while the stud seems } \\
\text { to have experienced overheating. } \\
\text { Overall, it seems to be negligibly affected (no visible corrosion } \\
\text { debris), while stud seems to have experienced overheating. }\end{array}$ \\
\hline Plain washer & $\begin{array}{l}\text { Set } 1 \\
\text { Set } 2\end{array}$ & $\begin{array}{c}\text { Major portion is severely corroded, having a rust-like appearance. } \\
\text { It does not seem to be affected at all. }\end{array}$ \\
\hline Spring washer & $\begin{array}{l}\text { Set } 1 \\
\text { Set } 2\end{array}$ & $\begin{array}{l}\text { It seems to be negligibly affected. } \\
\text { Major portion is severely corroded, having a rust-like appearance. }\end{array}$ \\
\hline Nut & $\begin{array}{l}\text { Set } 1 \\
\text { Set } 2\end{array}$ & $\begin{array}{l}\text { Major portion is moderately corroded. } \\
\text { Major portion is severely corroded, having a rust-like appearance. }\end{array}$ \\
\hline
\end{tabular}

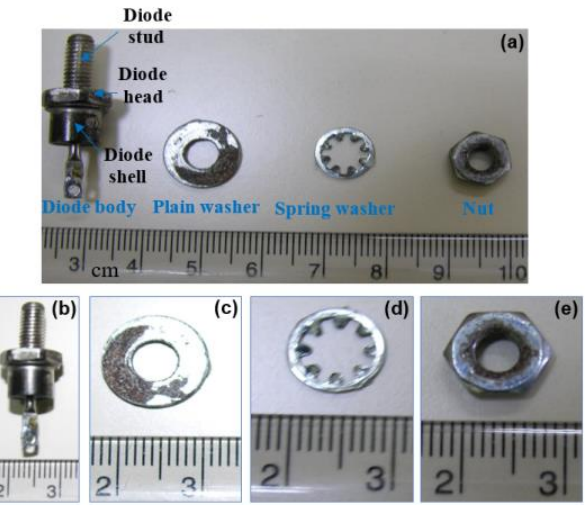

Figure 3: (a) Photographs of diode body, plain washer, spring washer and nut for set 1 diode assembly in the as-received condition showing corrosion with varying severity, (b-e) magnified views of the components.
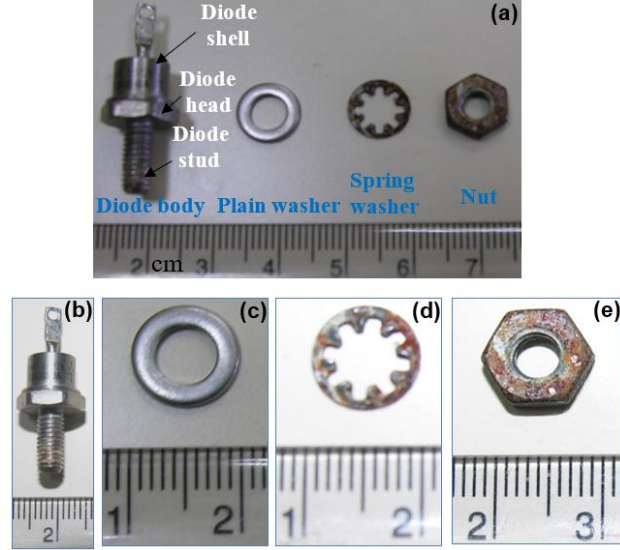

Figure 4: (a) Photographs of diode body, plain washer, spring washer and nut for set 2 diode assembly in the as-received condition showing corrosion with varying severity, (b-e) magnified views of the components.

\subsection{Metallographic Examination \\ Set 1 \\ Corrosion Product \\ Diode body}

The corroded debris on the shell surface was analysed by EDS in as-received condition (Figure 6). Magnified views of the shell cross-section near the coated region are displayed in Figure 6d,e. Those analyses reveal the presence of corrosion debris on both the coating and in the interior, containing largely $\mathrm{Fe}, \mathrm{O}$ and small amount of $\mathrm{Cl}$, as is confirmed by the EDS analysis of Figure $6 \mathrm{f}$. One more instance of observed corrosion debris is as shown in Figure $6 \mathrm{~g}, \mathrm{~h}$, where there is an apparent absence of the coating. Corrosion product on that place contains majorly Fe and $\mathrm{O}$, along with small amounts of $\mathrm{Cl}, \mathrm{K}$ and $\mathrm{Si}$, as is shown in Figure 6i. Not only that, it is also noteworthy that corrosion has occurred quite significantly along the MnS stringer-matrix interface and on the stringer itself, resulting in the eating away of the shell material, as has been shown in Figure 7a-c. Many a times, the corrosion paths (cracks) followed by those stringers and stringer-matrix interfaces are matching with the ferrite grain boundaries. 
Plain washer

The EDS analysis on the corrosion products of the as-received part is as shown in Figure 8b. It reveals the presence of $\mathrm{Zn}, \mathrm{Fe}, \mathrm{O}$ and $\mathrm{Si}$. The unetched as well as etched cross-sectional microstructure did not reveal the presence of any corrosion product. Figure $8 \mathrm{c}$ shows one etched photograph along an edge, in which no penetration of corrosion product into the structure was observed. It is also to be noted that the corrosion mechanism seems to be of uniform type and no pitting mechanism is present in this case.

\section{Spring washer}

This part does not seem to have experienced any corrosion, as is quite clear from the visual appearance. Figure $9 b$ is a cross-sectional optical micrograph of the part. Figure $9 \mathrm{c}$ is an SEM image. It is to be noted that there is a layer having different contrast to that of base material with average thickness of $5 \mu \mathrm{m}$. At locations, the layer thickness has been found to be as high as $20 \mu \mathrm{m}$. The EDS analysis of the region reveals the presence of $\mathrm{Zn}, \mathrm{Fe}$ and O, as shown in Figure 9d. It was also observed to possess pitted surface, as is shown in Figure 9e.

\section{Nut}

The corrosion product of the as-received part is as shown in the EDS result of Figure 10a. It reveals the presence of $\mathrm{Zn}, \mathrm{Fe}, \mathrm{O}$ and $\mathrm{Ni}$. The etched cross-sectional microstructure at some of the corroded regions reveals the presence of pitting, as is shown in Figure $10 \mathrm{~b}$.

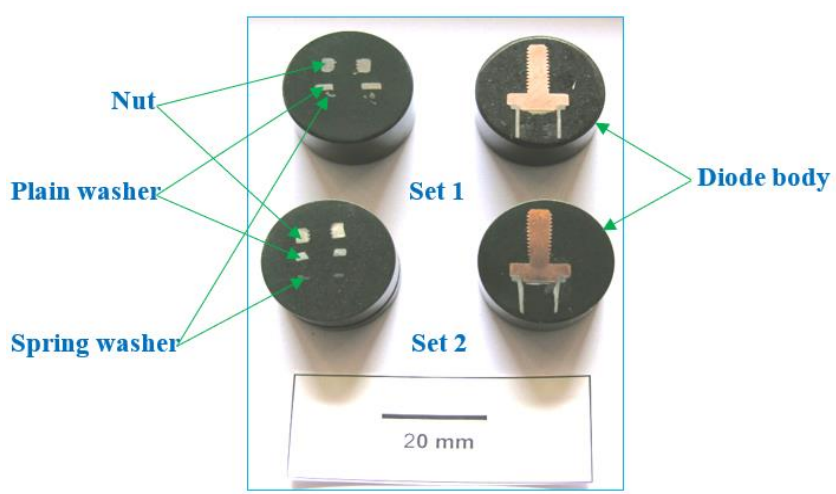

Figure 5: Cross-sectional samples after mounting in bakellite hot mount.

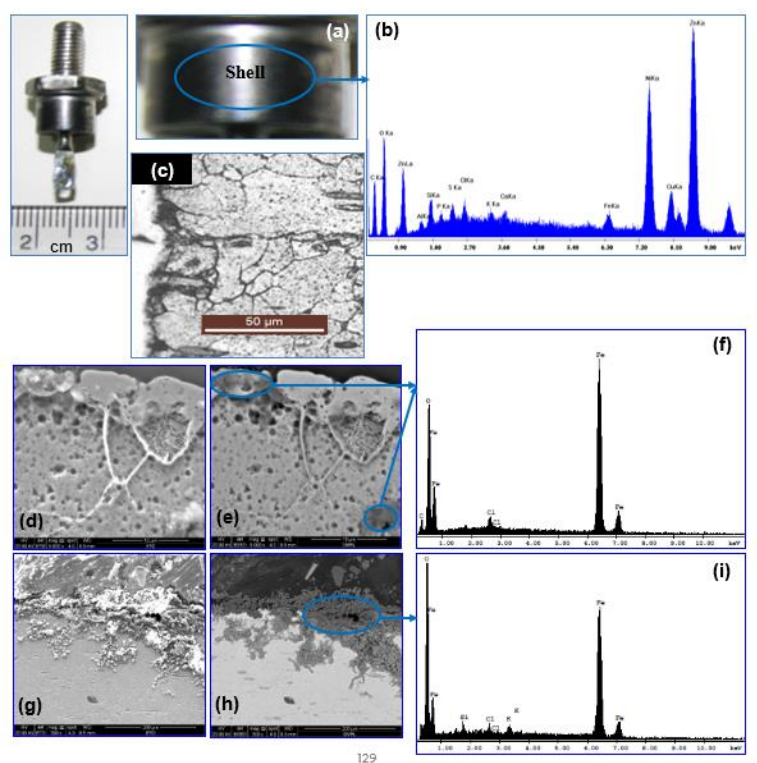

Figure 6: (a) Magnified photograph of the diode shell of Figure 3a,b in the as-received condition showing the corrosion, (b) EDS results of the corrosion debris sitting on the shell, (c) optical micrograph of the corroded shell, $(d, e)$ corrosion along the coating and deep inside the structure, (f) EDS analysis for the corrosion product shown in Figs. (d,e), (g,h) severe corrosion of the shell material along an edge in absence of coating, (i) EDS analysis for the corrosion product shown in Figs. (g,h). 

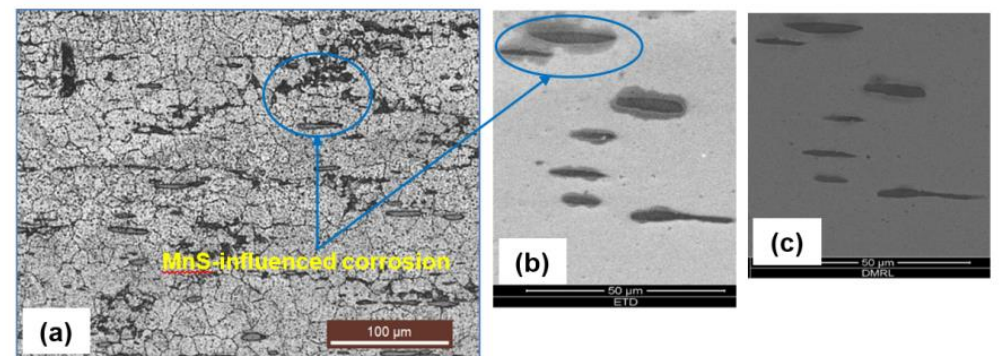

Figure 7: (a,b,c) Optical, SEM SE and SEM BSE micrographs respectively showing MnS stringer influenced corrosion along the stringer-matrix interface.

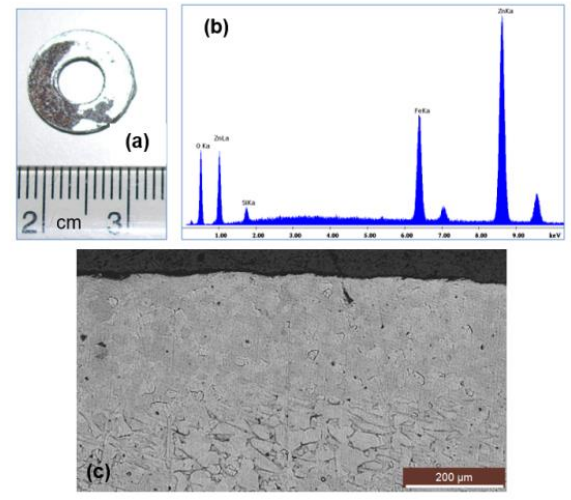

Figure 8: (a) As-received photograph of the plain washer of Figure 3a,c showing the corrosion, (b) EDS analysis result for the corrosion debris sitting on the surface, (c) etched optical micrograph along an edge in the cross-sectional view of the severely corroded region showing uniform corrosion and no penetration of the corrosion product deep into the structure.

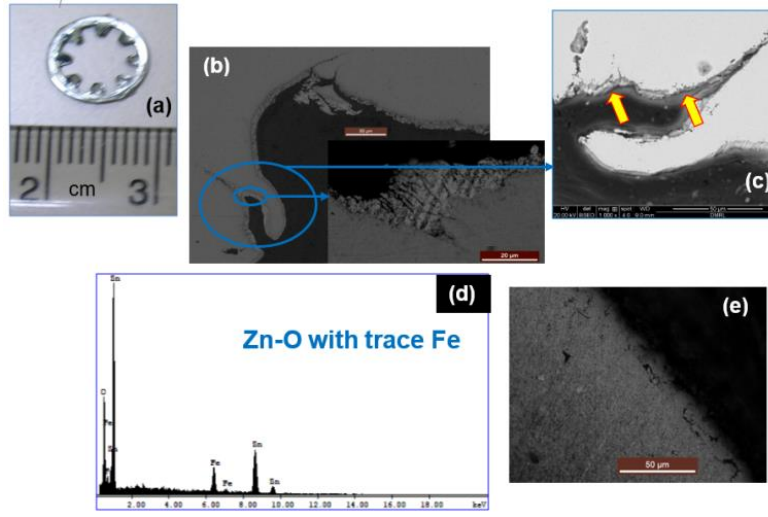

Figure 9: (a) As-received photograph of the spring washer of Figure $3 a, d$ showing the corrosion, $(b, c)$ respective optical and SEM BSE image showing corrosion products along an edge in the cross-sectional view, (d) EDS analysis result for the corrosion product shown in Figure $9 c$, (e) etched optical micrograph along an edge showing severe pitting.

Table 2: Chemical compositions of investigated failed (corroded) components

\begin{tabular}{ccccccccc}
\hline \multirow{2}{*}{ Component } & \multicolumn{7}{c}{ Chemical Compositions (Wt\%) } \\
\cline { 2 - 9 } & $\mathrm{C}$ & $\mathrm{S}$ & $\mathrm{P}$ & $\mathrm{Mn}$ & $\mathrm{Ni}$ & $\mathrm{Cr}$ & $\mathrm{V}$ & $\mathrm{Fe}$ \\
\hline Diode shell: Set 1 and Set 2 & 0.17 & 0.035 & 0.033 & 0.70 & - & - & - & Bal \\
Plain washer Set 1 & 0.08 & 0.048 & 0.040 & 0.45 & - & - & - & Bal \\
Plain washer Set 2 & 0.04 & 0.045 & 0.040 & 0.35 & 8.5 & 20 & - & Bal \\
Spring washer: Set 1 and Set 2 & 0.60 & 0.040 & 0.050 & & - & 0.75 & 0.12 & Bal \\
Nut: Set 1 and Set 2 & 0.40 & 0.045 & 0.038 & 0.65 & - & - & - & Bal \\
\hline
\end{tabular}

\section{Material}

Diode material has three major parts. Those are stud-head combination, ring and shell. The whole assembly was found to be coated by electroless nickel (EN) coating with phosphorous in the lowest range (2-5 wt.\%). Stud-head combination has been made from annealed bar stock of pure copper, while ring and shell have been made of annealed low carbon steel (Figure 11) of grade AISI 1018. Table 2 enlists the bulk chemical compositions for each of the components analysed in this investigation. The carbon steel of shell seems to be of free-machining variety, as evidenced by ample amount of MnS stringers in the microstructure (Figure 11). The shell and ring seems to be bonded by the diffusion bonding between two EN layers on the surfaces, while ring is joined to the stud head with the use of $\mathrm{Ag}$ - $\mathrm{Cu}$ - $\mathrm{Pb}$ filler alloy. $\mathrm{Fe}-\mathrm{Ni}$ and $\mathrm{Fe}-\mathrm{O}-\mathrm{Cl}$-rich products along some locations of the ring-shell interface may be the result of ingress of environmental $\mathrm{O}$ and $\mathrm{Cl}$ at the micro-gap between side stud head and shell. Plain washer has been machined from annealed low carbon steel bar stock conforming to AISI 1008 (Figure 12). The material for spring washer is a carbon steel of grade SAE 6160. It seems to be machined from an annealed bar stock and then hardened and tempered for use in service (Figure 13). Nut material has been machined from an extruded medium carbon steel $(\approx 0.4$ wt. \% C) and design profiles were given afterwards (Figure 14). This seems to correspond to AISI 1045. Each of the washers and nut was coated with electroplated zinc layer, as indicated by the layer thickness $(\approx 5 \mu \mathrm{m})[2]$. 


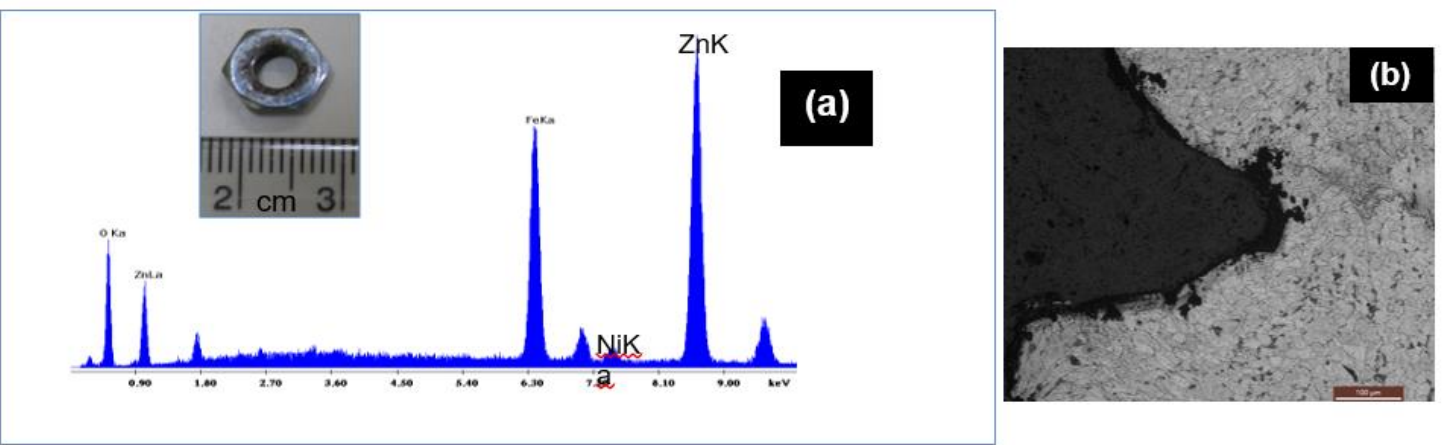

Figure 10: (a) EDS analysis result for the corrosion product sitting on the surface of nut (inset: as-received photograph showing the corrosion of nut) (b) etched optical micrograph along the threaded region showing moderate degree of pitting.
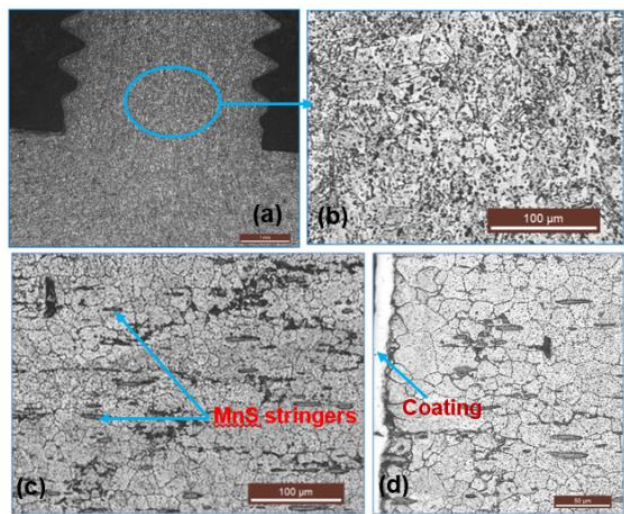

Figure 11: (a) Cross-sectional optical micrograph of the diode stud portion in etched condition, etchant: acidified potassium dichromate, (b) magnified view of the encircled region in Figure 11, (c) diode shell microstructure in etched condition showing MnS stringers, etchant: $2 \%$ nital, (d) etched shell microstructure in higher magnification showing whitish coating.
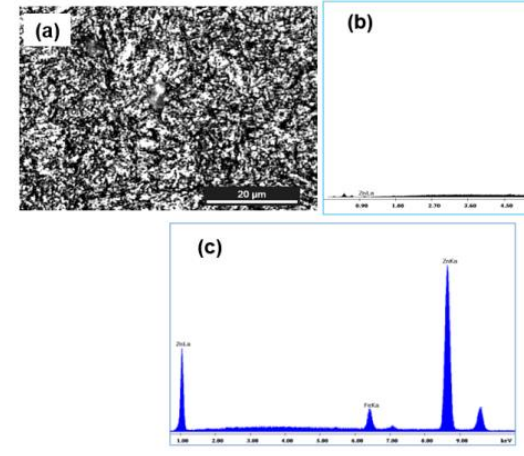

Figure 13: (a) Cross-sectional etched optical micrograph of the spring washer, etchant: 5\% nital, (b) EDS analysis of the base material for spring washer, (c) EDS analysis of the coating for spring washer.
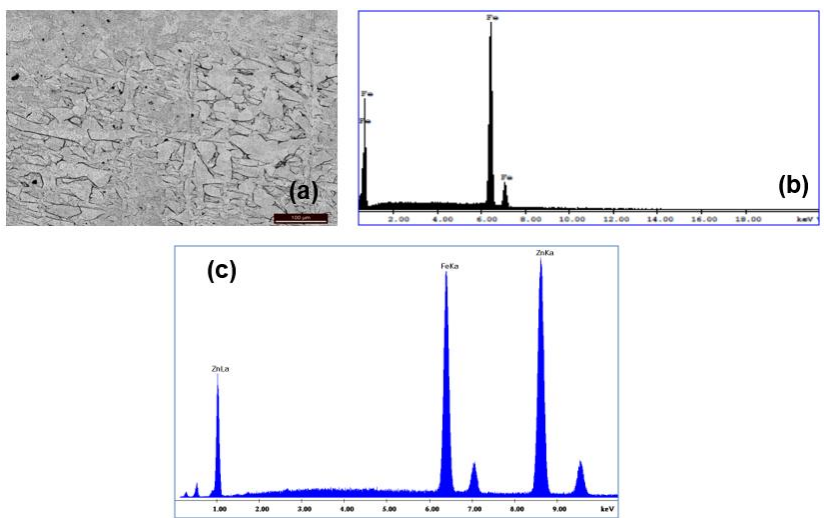

Figure 12: (a) Cross-sectional etched optical micrograph of the plain washer, etchant: $2 \%$ nital, (b) EDS analysis of the base material for plain washer, (c) EDS analysis of the coating for plain washer.

Inference: The diode shell has experienced severe corrosion with the as-received corrosion debris revealing the presence of $\mathrm{Zn}, \mathrm{Ca}, \mathrm{K}$, Fe and $\mathrm{O}$ beside the coating material ( $\mathrm{Ni}$ and $\mathrm{P}$ ). Presence of $\mathrm{Zn}$ indicates its transfer through corrosion product of other $\mathrm{Zn}$-plated components in the assembly, while $\mathrm{Ca}$ and $\mathrm{K}$ indicate the service environmental effect. However, presence of $\mathrm{Fe}$ and $\mathrm{O}$, at the same time, indicates slight rusting of the component. The cross-sectional micrographs along with the EDS results clearly points out the localized perforated/corroded and/or eroded EN 
coating and subsequent rusting within the coating as well as shell body [7,8]. The rust has been observed upto 25 $\mu \mathrm{m}$ depth from the coated surface. Additionally, one should note that coating perforation may have been also there as a result of improper plating process, as has been noticed in the high magnification SEM images, thus aggravating the severity of corrosion on the shell. MnS stringer-induced interfacial corrosion has also been observed here, likely due to the availability of the sufficient oxygen and presence of severe stress concentration along the interface. Both plain washer and nut have been found to be rusted, as evidenced by the presence of $\mathrm{Fe}$ and $\mathrm{O}$ in the corrosion product. Nonferrous metals such as zinc, nickel, aluminium, and magnesium do not contain iron and will not 'red rust'. Red rust only becomes visible after the sacrificial metal has been depleted. Therefore, the locations with the red appearance for the components plain washer and nut had definitely lost the sacrificial action of the coating because of its depletion and got exposed to the corrosive environment, resulting in rusting. Spring washer has not shown any visual evidence for corrosion and looked quite shiny. However, it is noteworthy that $\mathrm{Zn}-\mathrm{O}$ rich phase (usually coming as a result of $\mathrm{Zn}$-plating) with trace amount of $\mathrm{Fe}$, as obtained during the cross-sectional microstructural examination indicates the inception of corrosion process at some localized areas.

\section{Set 2}

\section{Corrosion products}

The configuration, type of material and coating for diode body, spring washer aild nut parts of set 2 have been found to be similar to those of set 1. Therefore, detailed representation by figures and texts for those parts are not placed here for set 2 (whenever deemed inappropriate) for avoidance of the repetition and improving upon the readability of this report.

\section{Diode body}

There was no corrosion debris sitting on the as-received diode body, as observed during visual inspection. However, corrosion product containing $\mathrm{Fe}$ and $\mathrm{O}$ has been detected, up to a depth of $100 \mu \mathrm{m}$ below the EN coating, while examining the cross-sectional sample. This has been shown in Figure 15a and corresponding EDS analysis is given in Figure 15b.

\section{Plain washer}

There was no corrosion product observed on the surface of the as-received part, as is presented in Figures $4 a, c$ and 16a. Figure 16b shows etched whole cross-sectional micrograph so as to look into and present the corrosion features of this part, if any. However, no signature of corrosion could be traced out, as is clearly seen in the micrograph.

\section{Spring washer}

This part had experienced severe corrosion, as is quite clear from the reddish surface appearance observed during visual inspection (Figure 4a,d and Figure 17a). That reddish deposit has been analysed in as-received condition and found to contain product rich in Fe and O, as is shown in Figure 17b. Figure 17c,d are the cross-sectional micrographs in unetched condition, revealing severe pitting of the part. Figure 17e is an optical micrograph in etched condition, showing etched layers along the edge with different contrasts to that of interior. In this image, both uniform attack (of $\approx 100 \mu \mathrm{m}$ depth) and pitting attack have been shown and the corrosion product has been found to be rich in Fe and $\mathrm{O}$ for both the form, as is shown by the EDS results in Figure 17f,g.

Nut

The corrosion product of the as-received part is as shown in the EDS result of Figure 18a along with the as-received photograph. Severe corrosion has been evidenced by the reddish surface appearance as well as the EDS results containing Fe, Zn, O, K, Ca, S, Si and Al. The etched SEM micrographs along the thread are shown in Figure 18(b,c) and $(d, e)$ in both SE and BSE modes. The imaging at different locations of the nut sample as well as the EDS analysis confirms the presence of Fe-O rich phases at both the threaded regions and deep inside the structure, as has been typified here.

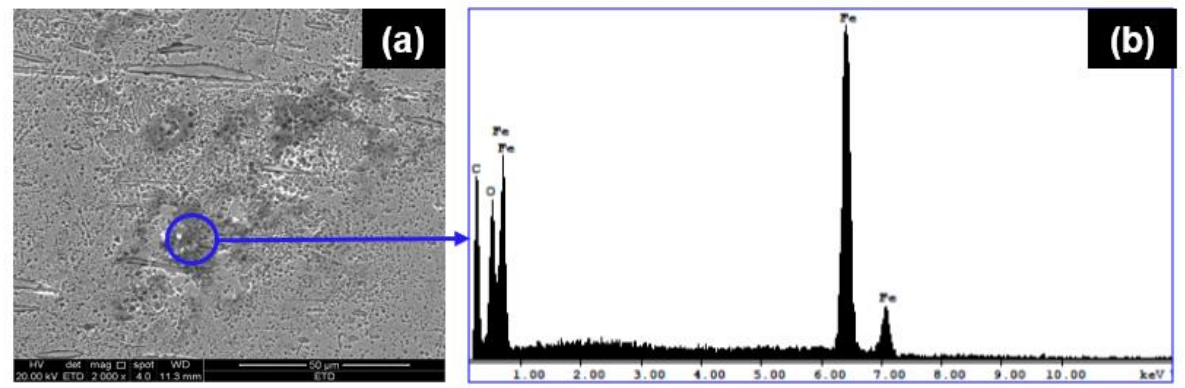

Figure 15: (a) Optical micrograph of the corroded shell showing corrosion deep inside the structure, (b) EDS analysis for the corrosion product shown in Figure 15a. 

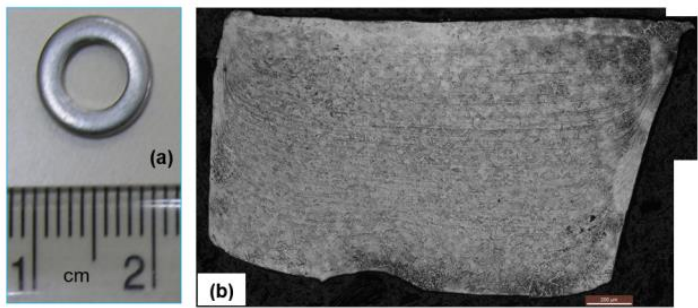

Figure 16: (a) As-received photograph of the plain washer of Figure 4a,c showing no sign of corrosion, (b) optical micrograph of the whole cross-section with no trace of corrosion, etchant: aqua-regia.
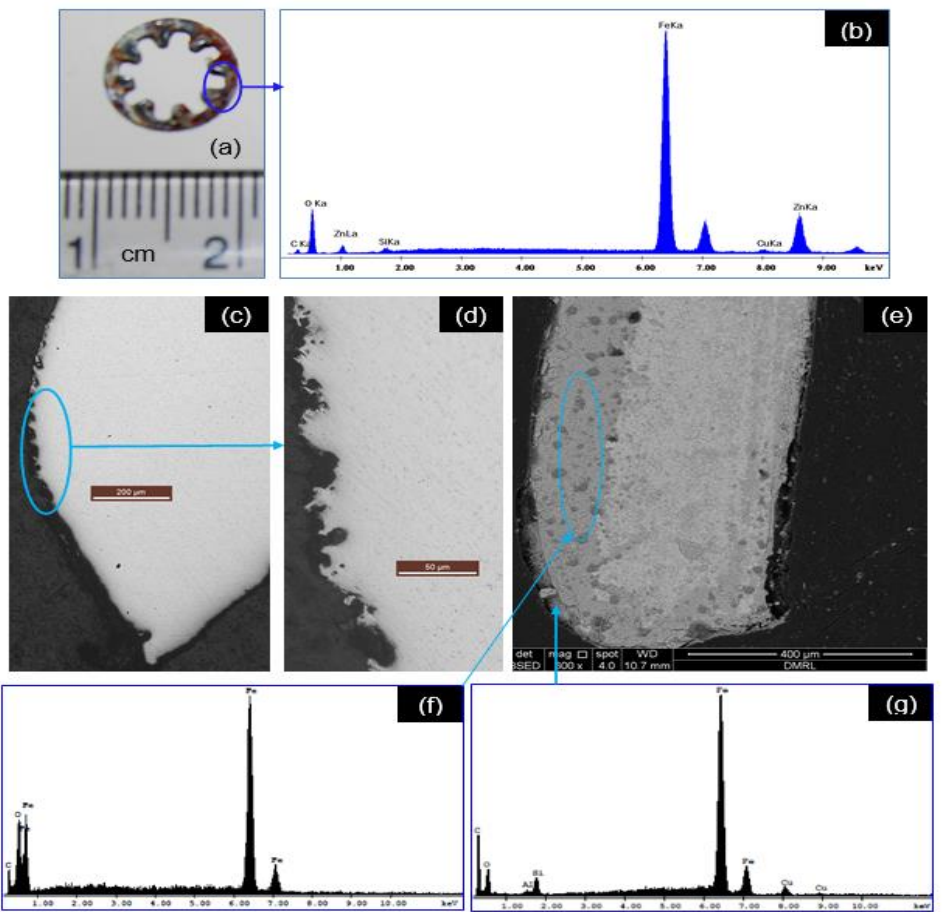

Figure 17: (a) As-received photograph of the spring washer of Figure 4a,d showing severe corrosion, (b) EDS analysis result for the corrosion debris on the as-received washer, $(c, d)$ unetched optical micrographs along an edge showing severe pitting, (e) etched optical micrograph showing uniform as well as pitting corrosion, $(f, g)$ EDS analysis results for the corrosion products shown in Figure 17e.

\section{Material}

Diode material consisted of three major parts, stud-head combination, ring and shell. The whole assembly is protected by electroless nickel (EN) coating with phosphorous in the lowest range (2-5 wt.\%). Stud-head combination has been made from drawn wire of annealed pure copper where upset forging type of operation has been applied for obtaining head part (Figure 19). Ring and shell have been made of annealed low carbon steel bar stock. The carbon steel of shell seems to be of free-machining variety with ample of MnS stringers in the microstructure, conforming to AISI 1018, as was the case for set 1 (Table 2). The shell and ring seem to be bonded by the diffusion bonding between two EN layers on the surfaces, while ring is joined to the stud head with the use of Cu-Sn-Fe base filler alloy. Fe-Ni$\mathrm{O}-\mathrm{S}$ - and $\mathrm{Ni}$-Fe-O-rich products along some locations of the ring-shell interface may be the result of ingress of environmental $\mathrm{O}$ and $\mathrm{S}$ at the micro-gap between side stud head and shell. The presence of Fe-Cu-P-Sn- and Fe-CuO-P-rich phases in the interface between ring and stud head have embrittled the structure locally and thus occasionally resulted in cracking, as has been seen through microstructural and hardness evaluation. Plain washer has been machined from solutionized austenitic stainless steel bar stock of AISI 316 type (Figure 20). The material for spring washer is a carbon steel conforming to SAE 6160. It seems to be machined from an annealed bar stock and then hardened and tempered for use in service (Figure 21). However, lower volume fraction of carbides and lower hardness value of the spring material for set 2 assembly than that for set 1 assembly indicates (low temperature) soft tempering treatment applied to the former unlike that to later. Nut material has been machined from an extruded medium carbon steel of grade AISI 1045 and design profiles were given afterwards (Figure 22). Each of the washers and nut was coated with electroplated zinc layer. Table 2 enlists the bulk chemical compositions for each of the components analysed in this investigation. 

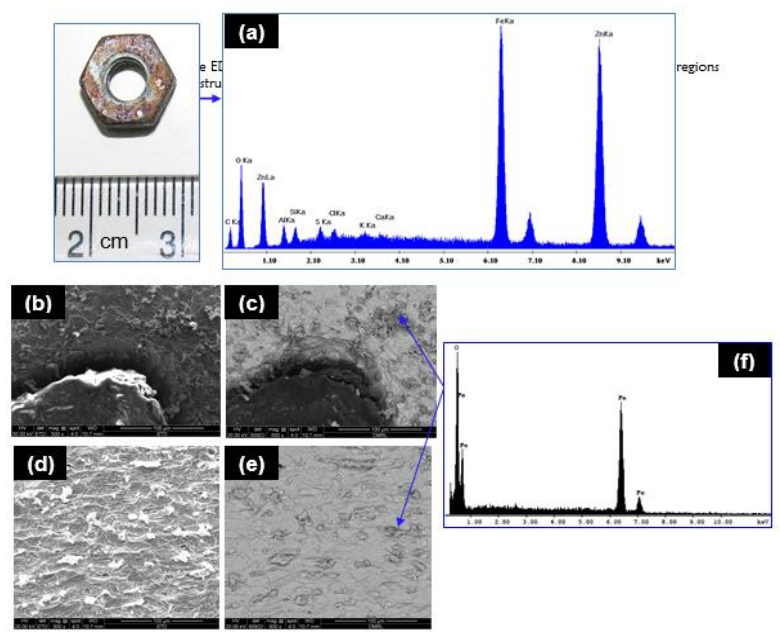

Figure 18: (a) EDS analysis result for the corrosion debris on the as-received nut, $(b, c)$ scanning electron micrographs along the threaded region under respective SE and BSE modes showing presence of corrosion products, (d,e) scanning electron micrographs away from the threaded region and deep into the structure under respective SE and BSE modes showing presence of corrosion products, (f) EDS analysis results for the corrosion products.
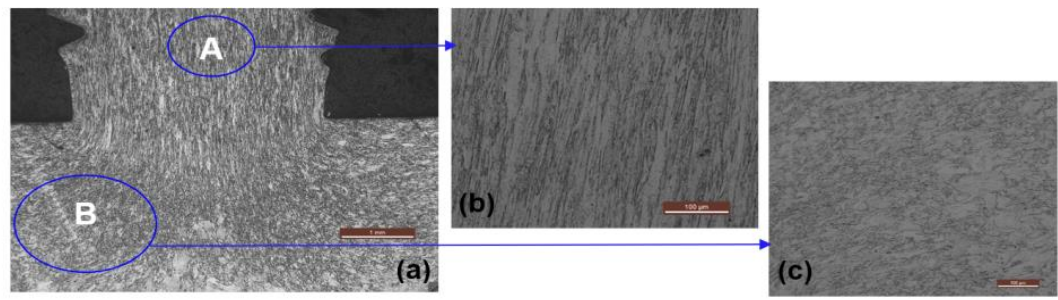

Figure 19: (a) Cross-sectional optical micrograph of the diode stud portion in etched condition, etchant: acidified potassium dichromate, (b) magnified view of the encircled regions in Figure 19a.

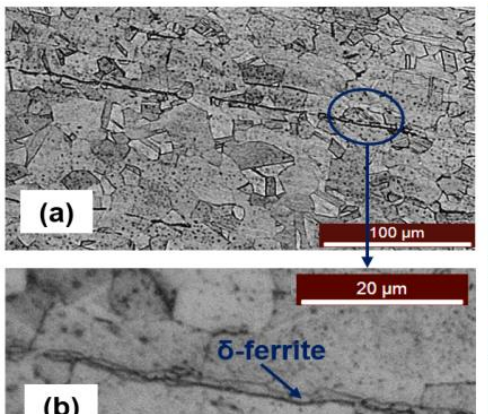

(b)

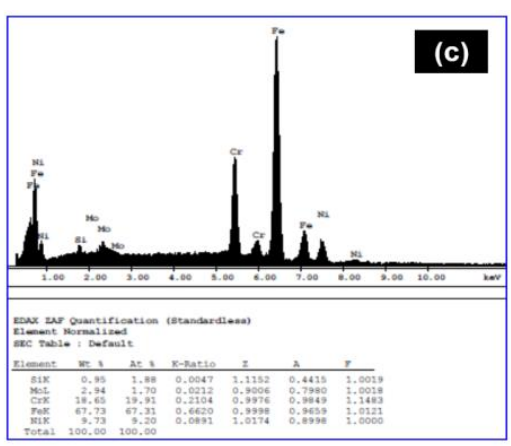

Figure 20: (a) Cross-sectional etched optical micrograph of the plain washer, etchant: aqua-regia, (b) magnified view of the encircled region showing chain like $\delta$-ferrite, (c) EDS analysis of the base material for plain washer.

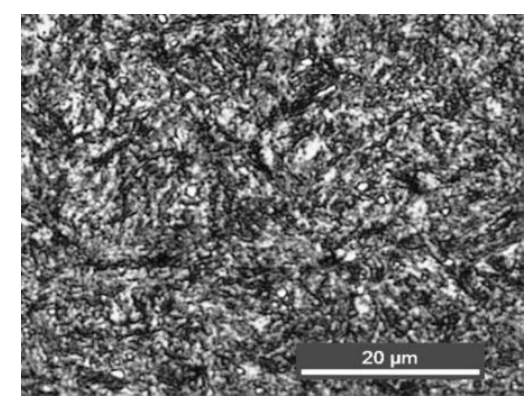

Figure 21: Cross-sectional etched optical micrograph.
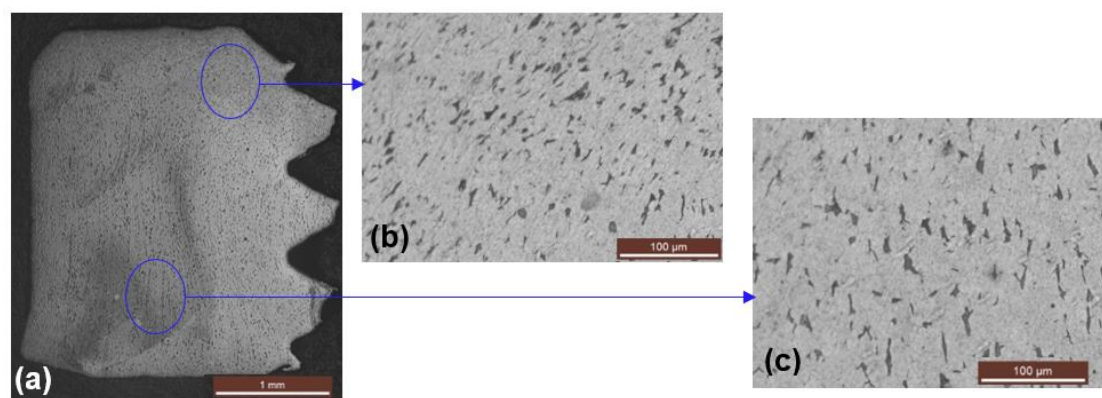

Figure 22: (a-c) Cross-sectional etched optical micrographs of the nut, etchant: $2 \%$ nital. 
Table 3: Vickers microhardness readings at 300gf (w.r.t. Figures 3, 4)

\begin{tabular}{ccc}
\hline \multicolumn{2}{c}{ Nomenclature (identification) of the parts } & Vickers microhardness $\left(\mathrm{HV}_{0.3}\right)$ \\
\hline \multirow{2}{*}{ Diode body* } & Set 1 & 56 (stud), 54 (head), 125 (shell), 315 (coating) \\
& Set 2 & 118 (stud), 118 (head), 130 (shell), 310 (coating) \\
Plain washer" & Set 1 & 139 \\
\multirow{3}{*}{ Spring washer } & Set 2 & 222 \\
& Set 1 & 392 \\
Nut & Set 2 & 422 \\
& Set 1 & 217 \\
& Set 2 & 206 \\
\hline
\end{tabular}

Inference: The diode shell has experienced inception of corrosion internally presumably due to the presence of perforation in the EN coating and/or local corrosion on coating and subsequently that of the shell material $[7,8]$. Another factor of great concern may be that the diode body was moderately corroded prior to the EN plating. MnS stringer-induced interfacial corrosion has also been observed here, likely due to the availability of the sufficient oxygen and presence of severe stress concentration along the interface. Spring washer has shown rusting - both in uniform and pit form. On the other hand, plain washer did not show any trace of corrosion due to the superior corrosion resistance of passivated/pre-oxidized AISI 316 type of stainless steel to that of Zn-coated low carbon steel. Nut has been found to be affected by corrosion deep into the structure and that manifested as reddish rusts on the surface.

\section{Hardness}

Micro hardness readings taken at $300 \mathrm{gf} \mathrm{load}$ are presented in Table 3 with reference to Figures 3-5. It is to be noted that each of the diode parts for both the sets revealed comparable hardness values except diode head and plain washers.

\section{CONCLUSIONS}

1. Inadequate electroless nickel (EN) plating along with significant amount of porosity and presence of MnS type of stringers affected the corrosion resistance of the diode body tremendously for both the diode sets.

2. Inadequate electroplated $\mathrm{Zn}$ layer was observed on spring washer and nut, wherein both uniform and pitting corrosion were detected for both the diode sets.

3. Inadequate electroplated $\mathrm{Zn}$ layer was also responsible for corrosion of plain washer of set 1 diode assembly, while stainless steel made plain washer (without coating) of set 2 assembly did not corrode at all.

4. The selection of stainless steel for plain washer in that case may have been without any logic and an accident, which saved the said washer and in turn may have aggravated the corrosion of other fasteners in contact significantly due to galvanic effect. Bulk material for each of the other fasteners for both the diode assemblies was of plain carbon steel type.

5. A summary of all the corrosion related findings for each fastener types for both the diode sets are tabulated in Table 4 for a quick and easy reference. This table may also prove to be very useful for relative comparison between traits of set 1 and set 2 components.

\section{RECOMMENDATIONS}

1. There should be periodic inspection of the subject components by the non-destructive evaluation methods, such as conventional X-Ray Fluorescence Spectroscopy (XRF), Automated Contact Resistance Probe (ACRP) etc. or advanced technique like Scanning Kelvin Probe (SKP) and its upgraded version Scanning Kelvin Force Microscopy (SKPM), Localised electrochemical impedance spectroscopy (LEIS) etc. [9]. This is to obtain quick ideas about the existence and nature of corrosion, if any, during service so as to avoid sudden failure of the subject component. These techniques can also contribute to the study of the galvanic effect in different materials, helping to the revelation of the precursor sites for the pit formation. The use of localised techniques can complement the results obtained with conventional electrochemical techniques, leading to a better comprehension of the corrosion processes.

2. Steel of the diode shell should be manufactured and processed in such a way so that an optimum shape (aspect ratio) of the MnS stringers is achieved for obtaining a balance between sufficient machinability and lower (matrixstringers) interfacial stress (and thus lower corrosion).

3. The electroless nickel coating applied on the diode body should be at least $25 \mu \mathrm{m}$ thick and with almost nil porosity level, which would like to improve the general as well as galvanic corrosion resistance of the underlying material [10].

4. The electroplated $\mathrm{Zn}$ layer may be replaced with galvanized $\mathrm{Zn}$ coating of higher thickness, so as to have better corrosion resistance, although aesthetic look may be of concern [2]. 
Table 4: Nature of corrosion types of various fasteners of two diode assemblies in comparative mode

\begin{tabular}{|c|c|c|c|c|}
\hline \multirow{2}{*}{\multicolumn{2}{|c|}{$\begin{array}{c}\text { Nomenclature } \\
\text { (identification) of } \\
\text { the parts }\end{array}$}} & \multicolumn{2}{|c|}{ Corrosion Phenomena } & \multirow[t]{2}{*}{ Remarks } \\
\hline & & \multirow{2}{*}{$\begin{array}{l}\text { Visual observation } \\
\text { Diode shell is tarnished } \\
\text { with a black product, } \\
\text { while the stud seems to } \\
\text { have experienced } \\
\text { overheating. }\end{array}$} & \multirow[b]{2}{*}{$\begin{array}{l}\text { Microstructural observation } \\
\text { Localized perforations in electroless } \\
\text { nickel (EN) coating on diode shell. } \\
\text { Corrosion debris containing } \mathrm{Zn}, \mathrm{Ca} \text {, } \\
\mathrm{K} \text {, Fe and O was found. Frequently } \\
\text { pitting and occasionally uniform } \\
\text { corrosion was observed. Rust was } \\
\text { observed up to } 25 \mu \mathrm{m} \text { depth from the } \\
\text { coated surface. Corrosion at MnS } \\
\text { stringer-base metal interfacial regions. }\end{array}$} & \\
\hline $\begin{array}{l}\text { Diode } \\
\text { body }\end{array}$ & Set 1 & & & 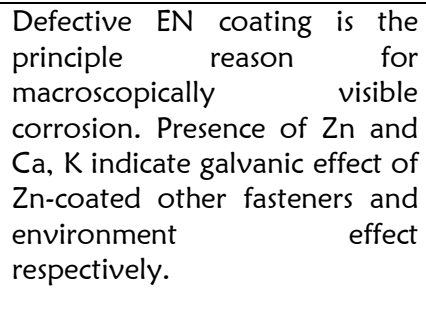 \\
\hline & Set 2 & $\begin{array}{l}\text { It seems to be negligibly } \\
\text { affected (no visible } \\
\text { corrosion debris), while } \\
\text { stud seems to have } \\
\text { experienced } \\
\text { overheating. }\end{array}$ & $\begin{array}{l}\text { Rust was observed up to } 100 \mu \mathrm{m} \\
\text { depth from the EN coated diode shell } \\
\text { surface. Nil observation of } \\
\text { perforation in EN coating, pitting } \\
\text { and/or uniform corrosion. Occasional } \\
\text { presence of MnS-induced corrosion. }\end{array}$ & $\begin{array}{l}\text { Diode body may have been } \\
\text { moderately corroded prior to } \\
\text { the EN plating. }\end{array}$ \\
\hline \multirow[t]{2}{*}{$\begin{array}{l}\text { Plain } \\
\text { washer }\end{array}$} & Set 1 & $\begin{array}{l}\text { Major portion is } \\
\text { severely corroded, } \\
\text { having a rust-like } \\
\text { appearance. }\end{array}$ & $\begin{array}{l}\text { Rusting was evident by presence of Fe } \\
\text { and } \mathrm{O} \text { in corrosion product. Uniform } \\
\text { corrosion type and no pitting was } \\
\text { observed. }\end{array}$ & $\begin{array}{l}\text { Localized in-service mechanical } \\
\text { damage of } \mathrm{Zn} \text { coating may have } \\
\text { been responsible for corrosion. }\end{array}$ \\
\hline & Set 2 & $\begin{array}{l}\text { It does not reveal any } \\
\text { sign of corrosion. }\end{array}$ & $\begin{array}{l}\text { No trace of corrosion, while } \\
\text { examined even microstructurally } \\
\text { under SEM. }\end{array}$ & $\begin{array}{l}\text { This is due to superior corrosion } \\
\text { resistance of passivated/pre- } \\
\text { oxidized AISI } 316 \text { type of } \\
\text { stainless steel (both uniform and } \\
\text { pitting type) to that of } \mathrm{Zn} \text { - } \\
\text { coated low carbon steel. }\end{array}$ \\
\hline \multirow[t]{2}{*}{$\begin{array}{l}\text { Spring } \\
\text { washer }\end{array}$} & Set 1 & $\begin{array}{l}\text { It seems to be negligibly } \\
\text { affected. }\end{array}$ & $\begin{array}{l}\mathrm{Zn}-\mathrm{O} \text { rich principal phase constituent } \\
\text { with trace amount of Fe was seen in } \\
\text { quite uniform thickness along major } \\
\text { part of the cross-sectional } \\
\text { microstructure. Pitting type of } \\
\text { corrosion was mainly seen. }\end{array}$ & $\begin{array}{l}\text { Inception of corrosion process } \\
\text { at some localized areas as a } \\
\text { result of sacrificial action of the } \\
\text { Zn coating. }\end{array}$ \\
\hline & Set 2 & $\begin{array}{l}\text { Major portion is } \\
\text { severely } \begin{array}{r}\text { corroded, } \\
\text { having a rust-like } \\
\text { appearance. }\end{array}\end{array}$ & $\begin{array}{l}\text { This has shown rusting - both in } \\
\text { uniform and pit form. However, no } \\
\text { product containing } \mathrm{Zn} \text { and/or O. }\end{array}$ & $\begin{array}{l}\text { Mechanical damage of } \mathrm{Zn} \\
\text { coating along major parts of the } \\
\text { component prior to its } \\
\text { installation in service may have } \\
\text { been responsible for corrosion. }\end{array}$ \\
\hline \multirow[t]{2}{*}{ Nut } & Set 1 & $\begin{array}{l}\text { Major portion is light to } \\
\text { moderately corroded } \\
\text { and light-reddish rust } \\
\text { like product was there } \\
\text { in the threaded region. }\end{array}$ & $\begin{array}{l}\text { Rusting was evident by presence of Fe } \\
\text { and } O \text { in corrosion product. Frequent } \\
\text { presence of pitting, and not uniform } \\
\text { corrosion was observed. }\end{array}$ & $\begin{array}{l}\text { Inception of corrosion process } \\
\text { at threaded regions as a result of } \\
\text { sacrificial action of the } \mathrm{Zn} \\
\text { coating. In other regions, } \\
\text { coating was intact and so no } \\
\text { corrosion. }\end{array}$ \\
\hline & Set 2 & $\begin{array}{l}\text { Major portion is } \\
\text { severely corroded, } \\
\text { having a strong reddish } \\
\text { rust-like appearance. }\end{array}$ & $\begin{array}{l}\text { It was found to be affected by } \\
\text { corrosion deep into the structure ( } 100 \\
\mu \mathrm{m} \text { from the surface) and that } \\
\text { manifested as reddish rusts on the } \\
\text { surface. Frequent presence of uniform } \\
\text { corrosion, and not pitting was } \\
\text { observed. }\end{array}$ & $\begin{array}{l}\text { Mechanical damage of } \mathrm{Zn} \\
\text { coating along major parts of the } \\
\text { component prior to its } \\
\text { installation in service may have } \\
\text { been responsible for corrosion. }\end{array}$ \\
\hline
\end{tabular}


6. The Ni-coated and $\mathrm{Zn}$-coated components should not be in contact for minimizing the galvanic effect between them [11]. Therefore, both the coating preferably should be of the same type. In this regard, Ni coating for all the components (as applied on critical diode body here) seems to be the best solution [12], if not cost-prohibitive with respect to the expected minimized corrosion damage.

7. For set 2 assembly, there should be thorough inspection for the remaining unplated diode bodies of the same lot, where corrosion may be prevailing in each of those components, as is found in the present analysis. And, in case of the existence of confirmed corrosion, those components should not be used in either unplated or in plated condition in service.

8. For set 2 assembly, plain washer of AISI 316 stainless steel type should not be clubbed with Zn-coated low carbon steel made spring washer and nut, wherein severe galvanic corrosion may result in. All those fasteners should be either of stainless steel type or of coated low carbon steel type. Both Zn-coated low carbon steel and passivated/pre-oxidized austenitic stainless steel may show same degree of corrosion resistance in some specific environments, however, the later would last longer than the former.

9. For set 2 assembly, stainless steel plain washer should not contain excess $\mathrm{Cr}(\approx 20 \mathrm{wt} . \%$ in this case) than is required $(12 \leq \mathrm{Cr} \leq 18$, in wt.\%, as in AISI 316$)$ for reasonable corrosion resistance. This is to avoid brittle $\delta$-ferrite phase formation, which may also affect the corrosion resistance of austenitic matrix by sucking more and more $\mathrm{Cr}$ into it. Schaffler diagram should be consulted for desired compositional balance in this regard [13]. Also, solutionizing temperature should be maintained within $1050-1100^{\circ} \mathrm{C}$ and soaking time should be reasonably low to avoid that phase.

\section{REFERENCE}

1. http://www.tesla-institute.com/, last accessed on 10.05.2018.

2. http://Www.surplus-electronics-sales.com/, last accessed on 10.05.2018.

3. Miksic, B.A., Martin, P.J. Proceedings of 6th European Symposium on Corrosion Inhibitors; Ferrara, Italy; 1985; 941-950.

4. Miksic, B.A., Vignetti, A. Vapour Corrosion Inhibitors: successful field applications in electronics. NACE Corrosion Conference; March 2000; Orlando; Paper \# 7, 2000.

5. Lee WY, Eldridge JM, Schwartz CC. Reactive ion ethching induced corrosion of Al and Al-Cu films. J Appl Phys 1981; 52: 2994.

6. Vimala, J. S., Natesan, M. and Rajendran, S. Corrosion and Protection of Electronic Components in Different Environmental Conditions - An Overview. The Open Corrosion Journal, 2009, 2, 105-113.

7. Ilangovan, S. Investigation of the mechanical, corrosion properties and wear behaviour of electroless Ni-P plated mild steel, International Journal of Research in Engineering and Technology, 2014, 03(04), 151-155.

8. Introduction to Surface Engineering for Corrosion and Wear Resistance (\#06835G), www.asminternational.org, last accessed on 10.05.2018.

9. Leiva-García, R., Sánchez-Tovar, R., Escrivà-Cerdán, C., García- Antón, J. Role of Modern Localised Electrochemical Techniques to Evaluate the Corrosion on Heterogeneous Surfaces, in Nanotechnology and Nanomaterials, Ed. M. Aliofkhazraei, June 11, 2014, ISBN 978-953-51-1586-1.

10. Deng, H., Moller, P. (1993), Effect of substrate surface morphology on the porosity of electroless nickel coatings, Transactions of the Institute of Metal Finishing, 2014, 71(04), 142-148.

11. Richard, T. Barrett, Fastener Design Manual, NASA Reference Publication 1228, 1990, last accessed on 10.05.2018.

12. Ünal, H. I., Zor, S., Gökergil, H.M. Corrosion behavior of $\mathrm{Zn}$ and Ni coated carbon steels in $3 \% \mathrm{NaCl}$, Protection of Metals and Physical Chemistry of Surfaces, 2013, 49(5), 591-596.

13. Robert E. Physical metallurgy principles, International Student Edition, 1972. 